\title{
6. ASTRONOMICAL TELEGRAMS
}

\author{
(TÉLÉGRAMMES ASTRONOMIQUES) \\ (Committee of the Executive Committee)
}

President: P. Simon.

Vice-President: J. Hers.

Director of THE BureaU: B. G. Marsden, Smithsonian Astrophysical Observatory, 60 Garden

Street, Cambridge, Massachusetts 02138, U.S.A.

Associate Directors of The Bureau: O. J. Gingerich, Z. Sekanina, R. B. Southworth.

\section{INTRODUCTION}

On 22 October 1922 IAU Circular No. 1 was issued from the Copenhagen Observatory by Elis Strömgren; on 20 October 1947 J. M. Vinter Hansen issued Circular No. 1112; and on 20 October 1972 Circular No. 2452 was issued from the Smithsonian Astrophysical Observatory by Brian G. Marsden. As is clear from the report below, the 50-year average of some 50 Circulars per year has been consistently exceeded in recent years, although in view of the tremendous growth in astronomical activity generally, this should scarcely be surprising. I am strongly impressed by this long and continuous cooperation among astronomers around the world, and it is a great pleasure for me to express my appreciation to all who have contributed to the activity of the Central Bureau.

Sadly, the date of the publication of the 50th-anniversary Circular was also that of the death of Harlow Shapley. Dr Shapley served as a member of Commission 6 for thirty years and was the initiator of the series of Harvard Announcement Cards, a subsidiary organ of the Central Bureau from 1926 until the Bureau was transferred from Copenhagen to Cambridge, Mass., at the end of 1964.

P. SIMON

President of the Commission

\section{REPORT OF THE CENTRAL BUREAU FOR ASTRONOMICAL TELEGRAMS}

The high level of activity of the preceding triennium was maintained - even surpassed - during 1970-72. This is especially reflected in the number of Circulars published, and it seems that we must now expect to publish more than 80 each year. A one-page and a two-page Circular are frequently distributed together, however, and the actual number of occasions on which Circulars were issued was not too substantially greater than during 1967-69. The number of 'telegram books' distributed has in fact been noticeably fewer. The statistics concerning the telegram books and the occasions on which Circulars were issued are:

\begin{tabular}{|c|c|c|c|}
\hline \multirow[b]{2}{*}{1970} & \multicolumn{2}{|c|}{ Telegrams } & Circulars \\
\hline & 40 & 61 & (Nos. 2197-2297) \\
\hline 1971 & 29 & 55 & (Nos. 2298-2379) \\
\hline 1972 & 38 & 63 & (Nos. 2380-2475) \\
\hline
\end{tabular}

The disparity between number of telegrams and number of Circulars must mainly be attributed to the fact that relatively few bright comets were discovered. To be sure, the year 1970 produced three spectacular naked-eye comets and four others easily visible with small telescopes; but, in addition, 
a record eleven periodic comets were recovered (eight of them by E. Roemer), and the Bureau was understandably much involved in publishing on the Circulars extensive ephemerides and lists of positional observations. From March 1971 to March 1972 no new comet was discovered at all, although this same interval saw nine periodic comets recovered.

The triennium has also seen a resurgence of interest in earth-approaching minor planets. Information pertaining to three new Apollo-type (1971 FA, 1971 UA and 1972 XA) and two new Amor-type (1972 RA and 1972 RB) objects was disseminated by both Circulars and telegrams; and ephemerides published in the Circulars led to the recoveries of $1948 \mathrm{EA}$ and $1968 \mathrm{AA}$. There has also been renewed interest in occultations by the planets and particularly by their satellites. News of a possible occultation by Pluto was relayed by the Bureau just a few days in advance, but no occultation seems to have taken place; on the other hand, the occultation of $\beta$ Sco C by Jupiter I in May 1971 was very successfully observed.

Novae and supernovae have continued to play an important role in the Bureau's activities. Five novae in our Galaxy and five in the Large Magellanic Coud were announced, while in May 1972 C. T. Kowal discovered the fourth brightest extragalactic supernova on record. The Bureau has also been concerned with what may be termed the inverse process $-\mathrm{R} C \mathrm{CB}$ variables undergoing minima.

As could perhaps have been anticipated, the Bureau has been less involved than before with discovery announcements of pulsars. On the other hand, the Circulars have contained a number of items on the identification of interstellar molecules. The advisability of disseminating information of this kind by IAU Circular has again been questioned, the solution apparently being that the material should be so published, provided that its volume does not get completely out of hand. Many of the items on X-ray sources would appear to be in the same category, although the transient nature of several of the events associated with these sources sometimes makes publication in the Circulars very desirable indeed.

A few slight changes have been made in the arrangements for handling telegrams, the principal one being that cutbacks have forced the closure of the Smithsonian Astrophysical Observatory's Communications department between midnight and $8 \mathrm{a}$ a.m. This change has had little effect in practice, however, for incoming messages were rarely passed on to the Central Bureau during these hours anyway. Telegrams are now relayed to Dr P. Simon at Meudon (for subsequent distribution to all of Europe except for The Netherlands and the U.S.S.R.) via a NASA circuit and CNES in Paris; those bound for South Africa also go by a NASA circuit and thence to the ex-Republic Observatory. The unavailability of U.S. government lines to Argentina has meant that messages must be sent there by commercial cablegram.

The promised change that would put the billing system for the Circulars on a calendar basis is still not a reality, principally because of the problem of obtaining adequate programming assistance. The North American subscription price to the Circulars was increased in May 1971 to take into account increased postal rates, but no change was made when the overseas postal rates were adjusted two months later. On the other hand, overseas subscribers to the telegrams are now paying a surcharge of up to $10 \%$ in order to help defray the costs of processing the telegrams.

International postal regulations now render multiple postcards unacceptable for mailing to points outside North America. For this reason we have recently been sending to overseas subscribers all but the single one-page Circulars in window envelopes. Since these envelopes are marked with airmail stripes, it is no longer possible for persons and observatories outside North America to subscribe to the Circulars at the surface-mail prices.

By arrangement with Commission 20, a new Catalogue of Cometary Orbits was issued in March 1972 as a special publication of the Central Bureau. Prepared almost entirely by photographic offset printing from computer output, the 70-page catalogue has been selling for $\$ 2.50$ ( $\$ 4.00$ to those overseas who wish to receive it by airmail). I. Hasegawa has handled most of the distribution in Japan, the British Astronomical Association most of the distribution in the United Kingdom. Nine months after the initial publication some 700 of the 1000 copies printed had been sold.

Except for continued subsidy from the Smithsonian Astrophysical Observatory in the form of personnel, the financial situation of the Central Bureau is reasonably good. The IAU subvention of 
$\$ 533$ per year is a very welcome additional support, and it is used partly to ensure that Circulars are supplied to important observatories in regions of the world whence it is difficult or impossible for us to receive payment.

B. G. MARSDEN

Director of the Bureau

\section{APPENDIX}

A further slight change has been made in the code for astronomical telegrams (see Trans. IAU, XIIC, pp. 34-38; XIIIA, pp. 1xxxii-1xxxiii; XIVA, p. 17).

On Circular No. 2275 we proposed the temporary adoption of a slash $(/)$, rather than a hyphen $(-)$, as the character for a suppressed digit. It would now appear that this change can be made permanent. However, as noted on Circular No. 2293, trouble arises when a complete group of five slashes is transmitted. This would most commonly occur in the case of the group referring to the time of observation, and it was proposed that, if the time is unspecified, that whole group should be omitted. (Persons telegraphing observations are urged to supply sufficient information that no other group would have to contain five slashes.) Further, since the first character in the magnitude group is always redundant for approximate positions, that character is now to be given as zero (0). 